Original Article

Artigo Original

Ana Rita Gatto ${ }^{1}$

Paula Cristina Cola ${ }^{2}$

Roberta Gonçalves da Silva ${ }^{3}$

André Augusto Spadotto ${ }^{4}$

Priscila Watson Ribeiro ${ }^{5}$

Arthur Oscar Schelp ${ }^{5}$

Lidia Raquel de Carvalho ${ }^{6}$

Maria Aparecida Coelho de Arruda Henry²

Keywords

Citrus

Cold temperature

Deglutition disorders

Deglutition

Stroke

Descritores

Acidente cerebral vascular Citrus

Deglutição

Transtornos de deglutição Temperatura baixa
Correspondence address:

Ana Rita Gatto

R. Dr. Darwin do Amaral Viegas, 40, Botucatu (SP), Brasil, CEP: 18607-680.

E-mail: argatto@hotmail.com

Received: 6/28/2011

Accepted: 9/13/2012

\section{Sour taste and cold temperature in the oral phase of \\ swallowing in patients after stroke}

\section{Sabor azedo e temperatura fria na fase oral da deglutição no acidente vascular encefálico}

\begin{abstract}
Purpose: To determine the effect of sour flavor and cold temperature on oral transit time during swallowing. Methods: Participants were 52 subjects (28 male and 24 female) with ages between 50 and 80 years (median=66 years), after ischemic stroke involving right or left side damage and mild to moderate oropharyngeal dysphagia. Videofluoroscopy was performed to analyze the swallowing times. Each subject was assessed during swallowing of a paste consistency bolus offered in $5 \mathrm{ml}$ spoons, with a total of four different stimuli (natural, cold, sour and sour-cold). After the exam, the oral transit time was measured using specific software. The oral transit time (starting at the beginning of the bolus movement in the mouth) and the total oral transit time (starting at the moment that the bolus is placed in the mouth) were measured. Results: The association between sour and cold stimuli caused a significant decrease of oral transit time and total oral transit time. Conclusion: Sour flavor and cold temperature reduced oral transit time in stroke patients.
\end{abstract}

\section{RESUMO}

Objetivo: Verificar o efeito do sabor azedo e da temperatura fria no tempo de trânsito oral da deglutição. Métodos: Participaram deste estudo 52 indivíduos (28 do gênero masculino e 24 do gênero feminino) após acidente vascular encefálico isquêmico, com lesão à direita ou à esquerda e disfagia orofaríngea de grau leve a moderado, com idades variando de 50 a 80 anos (mediana=66 anos). Foi realizada a videofluoroscopia da deglutição para a análise dos tempos de deglutição. Cada indivíduo foi avaliado durante a deglutição de bolo na consistência pastosa, oferecido em colher com $5 \mathrm{ml}$, com quatro estímulos diferentes (natural, frio, azedo e azedo-frio). Após o exame foram realizadas as medidas de tempo de trânsito oral utilizando software específico. Foram mensurados o tempo de trânsito oral (a partir do início do movimento do bolo alimentar na boca) e o tempo de trânsito oral total (a partir do momento em que o bolo é colocado na boca). Resultados: A associação entre o estímulo azedo e a temperatura fria provocou mudanças significavas no tempo de trânsito oral total e no tempo de trânsito oral, com redução nestes tempos. Conclusão: O sabor azedo e a temperatura fria associados apresentaram redução do tempo de trânsito oral em pacientes pós acidente vascular encefálico.

Study carried out at the Botucatu Medical School, Universidade Estadual Paulista "Júlio de Mesquita Filho" UNESP - Botucatu (SP), Brazil.

(1) Department of Neurology and Psychiatry, Botucatu Medical School, Universidade Estadual Paulista "Júlio de Mesquita Filho" - UNESP - Botucatu (SP), Brazil.

(2) Department of Surgery, Botucatu Medical School, Universidade Estadual Paulista "Júlio de Mesquita Filho" - UNESP - Botucatu (SP), Brazil.

(3) Department of Speech-Language Pathology and Audiology, Marília College of Philosophy and Sciences, Universidade Estadual Paulista "Júlio de Mesquita Filho" - UNESP - Marília (SP), Brazil.

(4) Department of Electrical Engineering, School of Engineering, Universidade de São Paulo - USP - São Carlos (SP), Brazil.

(5) Department of Neurology and Psychiatry, Botucatu Medical School, Universidade Estadual Paulista "Júlio de Mesquita Filho" - UNESP - Botucatu (SP), Brazil.

(6) Department of Bioestatistic, Botucatu Medical School, Universidade Estadual Paulista "Júlio de Mesquita Filho" - UNESP - Botucatu (SP), Brazil.

Conflict of interest: nothing to declare. 


\section{INTRODUCTION}

Human swallowing is a complex and coordinated function ${ }^{(1)}$. Sensory information coming from food and saliva is important to start and modulate swallowing. Some properties of the food bolus, such as temperature, volume and texture, are known to modulate swallowing behavior by adapting biomechanical and temporal mechanisms ${ }^{(2-5)}$.

Swallowing difficulty is a common deficit in patients after stroke, impairing normal swallowing physiology. According to a study ${ }^{(6)}$, the sensory deficit is one of the main causes of neurogenic dysphagia in this population.

The incidence of dysphagia in post-stroke patients is high, affecting $50 \%$ or more of the cases ${ }^{(7,8)}$. For these patients, dysphagia is not only disabling because it affects their diet, nutritional and hydration aspects, but also because it may be the potential cause of serious complications, such as dehydration and aspiration pneumonia. These complications demonstrate the importance of rehabilitation and monitoring of post-stroke patients.

Delay or absence of pharyngeal phase onset, slow oral transit, and laryngeal penetration are strong markers of risk for complications subsequent to dysphagia in post-stroke patients ${ }^{(8)}$. Some studies have observed an increase in oral phase transit ${ }^{(9)}$ and a delay in the swallowing onset ${ }^{(10)}$.

In a recent study with post-stroke patients ${ }^{(11)}$, it was observed that abnormal pharyngeal transit time, duration of laryngeal closure, and time of pharyngeal response, taken together, are the best predictive values of aspiration risk. The authors concluded that the reduction of these times, or favorable changes in these parameters, could reduce the aspiration risk in this population.

Taking these data into account, studies have tried to understand the types of stimulation that would benefit these patients, facilitating the rehabilitation of oropharyngeal swallowing.

In this context, temperature, volume and texture are known to modulate swallowing behavior ${ }^{(9,12)}$. Other studies have tried to expand and deepen the investigation in this area, trying to understand the actual role of taste and its different intensities on the swallowing function ${ }^{(13-15)}$.

Taste is an important oral-sensory stimulus and sour taste, in particular, has been known to be able to increase pre-swallowing sensory inputs to the cortex and brainstem, reducing the swallowing threshold response ${ }^{(13)}$. When the threshold is reduced, a reduction in oral transit time and also a faster pharyngeal response are expected to occur, which may minimize the risks of laryngeal penetration and/or aspiration.

However, a review of the literature on dysphagia reveals results which are, to some extent, contradictory or inconclusive. For example, according to some studies ${ }^{(13,16,17)}$, sour taste causes favorable changes in swallowing, such as a reduction of time to the onset of the oral phase, reduction of the delay to trigger swallowing, reduction of pharyngeal transit time, and frequency of aspiration. However, different results were shown in another study ${ }^{(14)}$, in which there was reduction of swallowed volume and swallowing rate, especially when associating cold and sour taste. These different results may be due to the different methodologies applied, different sour concentrations and different consistencies ${ }^{(14)}$.
Our hypothesis was that the increase of sensory inputs provided by an intense taste (sour) and cold temperature would lead to reduced oral transit time and onset of swallowing, due to facilitating bolus perception and oral control. Therefore, the objective of the present study was to investigate the effect of sour taste, cold temperature and the combination of these stimuli on the oral phase of swallowing in patients after unilateral ischemic stroke.

\section{METHODS}

\section{Sample}

The study was conducted on 52 patients after ischemic stroke with right $(\mathrm{R})$ and left $(\mathrm{L})$ side damage and mild to moderate oropharyngeal dysphagia ${ }^{(18)}$. Twenty-eight were men and 24 were women, right-handed, aged 50 to 80 years (median $=66$ years, $\mathrm{SD}=11$ months). Of these 52 patients, 33 patients were in the first week after stroke (1-7 days), 13 patients in the second week after stroke (8-14 days), and six patients in the two following weeks (15-30 days).

These patients were divided into two groups depending on the sequence of offered stimuli: Group 1 - randomly supplied stimuli (24 patients); Group 2 - stimuli offered in the following order: natural, cold, sour and cold-sour (28 patients). Group 1 consisted of 24 subjects, 12 men and 12 women, nine with hemispheric lesion on the right and 15 on the left. Group 2 consisted of 28 subjects, 16 men and 12 women, 14 with right side lesion and 14 with left side lesion.

The 52 patients were also divided by time of occurrence of stroke (ictus). The subjects were divided by week. In the first week the subjects $(n=33)$ had an ictus from 1 to 7 days, in the second week the subjects $(n=13)$ had an ictus from 8-14 days and the third and fourth week $(n=6)$, the ictus were from 15 to 30 days.

The study protocol was approved by the Research Ethics Committee of Medical School of Botucatu (OF. 284/2007) and all subjects or their legal representatives gave written informed consent to participate.

Patients with the following characteristics were excluded from the study: hemorrhagic stroke, subjects who used medication that could interfere with swallowing dynamics, subjects with a previous stroke history to this occurrence (stroke), impairment of conscious level, and subjects with unstable general clinical status confirmed by medical assessment.

\section{Methods}

All subjects in this study underwent clinical neurological assessment, speech clinical assessment and objective examination of swallowing (videofluoroscopy swallowing). The neurological diagnosis of ischemic stroke and cortical impairment was made by clinical neurological assessment and confirmed by neuroimaging exams, such as computed tomography and/or magnetic resonance imaging. The time between the occurrence of the stroke and enrollment in the study ranged from one to 30 days (median $=6$ days). 
The times of swallowing events were analyzed by swallowing videofluoroscopy. During swallowing videofluoroscopic assessment, the subjects remained seated in a lateral position. The anatomical limits visualized in videofluoroscopic images were: upper and lower limits from the oral cavity to the esophagus, with the lips representing the anterior limit, the pharyngeal wall the posterior limit, the nasopharynx the upper limit, and the esophagus the lower limit ${ }^{(19)}$.

The equipment used was a Prestilix tele-commanded seriographer, model 1600X, $1000 \mathrm{MA}, 130 \mathrm{KV}-\mathrm{GE}^{\circledR}$. Images were transmitted through a Sony ${ }^{\circledR}$ videomonitor, model PVM-95E. Exams were videotaped using a Panasonic ${ }^{\circledR}$ SVHS videocassette, model AG 7400 .

Each subject was observed during swallowing of a $5 \mathrm{~mL}$ spoonful of paste consistency comprising a total of four stimuli (natural, cold, sour and sour-cold). Paste consistency was preferred for videofluoroscopy because it is considered safer for subjects in this group ${ }^{(20)}$.

Patients were previously instructed to swallow naturally, i.e., disregarding the command to swallow, but swallowing naturally by placing the food in the mouth and starting to swallow immediately. Between one stimulus and the other, the patients performed spontaneous swallows following the stimulus. The procedure lasted, in average, 30 seconds, before the next stimulus was provided.

The paste consistency bolus was prepared using $4 \mathrm{~g}$ of the Thick \& Easy ${ }^{\circledR}$ thickening product (Hormel Health Labs. USA), consisting of a combination of carbohydrates and minerals, containing $360 \mathrm{kcal} / 100 \mathrm{~g}$, added to water $(40 \mathrm{~mL})$ and diet juice, lemon flavor $(3 \mathrm{~g})$. The boluses were offered at two temperatures, i.e., room $\left(22^{\circ} \mathrm{C}\right)$ and cold $\left(8^{\circ} \mathrm{C}\right)$ temperature.

\section{Definition of quantitatively analyzed parameters}

- Oral Transit Time (OTT): OTT was defined as an interval in milliseconds between the first frame showing the beginning of the food bolus movement in the mouth and the first frame showing the proximal portion (head) of the food bolus in the hypopharynx, or the point where the lower margin of the mandible crossed the tongue base ${ }^{(13)}$ (Figure 1).

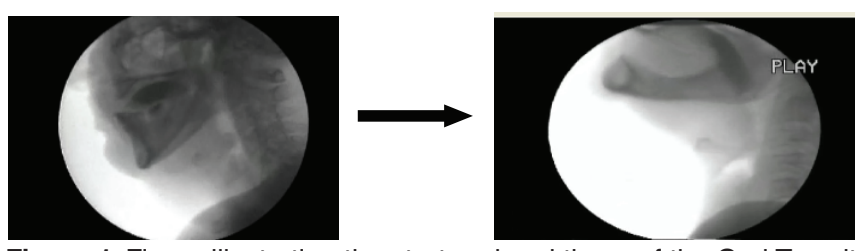

Figure 1. Figure illustrating the start and end times of the Oral Transit Time

- Total Oral Transit Time (TOTT): this parameter, the count started at the time that the bolus is placed in the mouth, regardless of the onset of food bolus movement inside the mouth. Therefore the TOTT was defined as an interval in milliseconds between the first frame showing the food inside the oral cavity and the first frame showing the proximal part (head) of the food bolus in the hypopharynx or the point where the lower margin of the mandible crossed the tongue base (Figure 2).

To analyze these parameters specific software that provided the time analysis in milliseconds was used, permitting frameby-frame analysis of the exams in slow motion, or at conventional speed ${ }^{(21)}$. This software was design with functions based in frames removed from the videofluoroscopy exams, i.e., it can be used to quantify more precisely the data ${ }^{(21)}$.

The exams were analyzed by two speech-language pathologist examiners with the same type of education and training in oropharyngeal dysphagia and trained in swallowing videofluoroscopy for nine years.

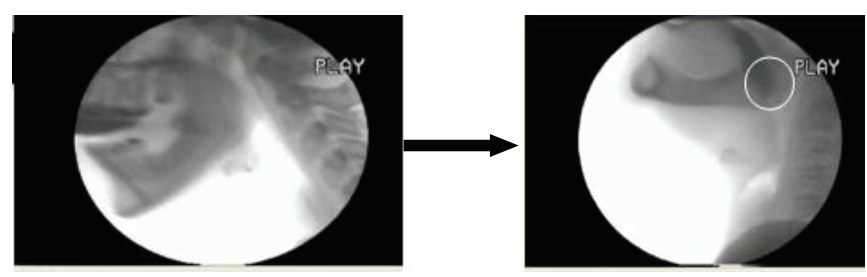

Figure 2. Figure illustrating the start and end times of the total oral transit time

\section{Statistical analysis}

The examiners performed separate analysis of random and non-random sets. Since there were no differences between examiners, their mean values were used for statistical analysis.

Comparative analysis between random and non-random sets was performed. Additionally, it was performed a comparative analysis by time of occurrence of stroke. Both analyses showed no difference between groups, leading to a single joint analysis.

Since the variables did not have normal distribution, nonparametric analyses were made, i.e., the Friedman test was used for each set and later one test was applied to both.

The level of significance was $5 \%$.

\section{RESULTS}

Statistical analysis showed that the measurements made by the two examiners did not present difference, and that the groups analyzed also did not differ from each other. Therefore, we used the mean of the two examiners and the combination of both groups for statistical analysis, as shown in Table 1 .

Table 1 lists the median OTT and TOTT according to the stimuli (natural, cold, sour and sour-cold). The sour-cold stimulus presented statistically shorter TOTT and OTT when compared to the natural stimulus.

\section{DISCUSSION}

The main result was that only combined sour-cold stimuli caused significant changes in TOTT and OTT, as shown in Table 1. Regarding a cold stimulus alone, the results of our study were similar to those in literature, indicating that this bolus has no effects on swallowing behavior ${ }^{(14,22)}$. 
Table 1. Oral Transit Time and Total Oral Transit Time by stimuli

\begin{tabular}{|c|c|c|c|c|c|}
\hline \multirow{3}{*}{ Measure } & \multicolumn{4}{|c|}{ Stimuli } & \multirow{3}{*}{$\mathrm{p}$-value } \\
\hline & Room temperature & Cold & Sour & Sour/Cold & \\
\hline & Median [1Q, 3Q] & Median [1Q, 3Q] & Median [1Q, 3Q] & Median [1Q, 3Q] & \\
\hline TTO (in ms) & $2631[1719,6482] a$ & $2412[1666,4144]^{\mathrm{ab}}$ & $2445[1333,4165]^{\mathrm{ab}}$ & $1995[1215,3968]^{b}$ & $<0.05$ \\
\hline TTOT (in ms) & $3689[2185,5336]^{\mathrm{a}}$ & $3098[2011,4796]^{\mathrm{ab}}$ & $3128[1632,4501]^{\mathrm{ab}}$ & $2661[1639,4456]^{\mathrm{b}}$ & $<0.05$ \\
\hline
\end{tabular}

Friedman test $(\mathrm{p}<0.05)$; Stimuli followed by the same letter did not show statistical difference

Legends: OTT $=$ oral transit time; TOTT = total oral transit time; $1 \mathrm{Q}=$ first quartile; $3 \mathrm{Q}=$ third quartile

Few studies focusing on the use of associated chemical and thermal stimuli were found in literature ${ }^{(14,22)}$. In these studies, similar to ours, the combination between sour and cold have modified swallowing behavior.

In contrast with our results, a study ${ }^{(13)}$ observed that the time of onset of swallowing, as well as OTT, was reduced in the presence of a sour stimulus alone. In our study, even though OTT and TOTT were mostly shorter for a sour stimulus than for a natural stimulus, the difference was not statistically significant (Table 1). This difference was only detected in the presence of combined sour and cold stimuli. Similarly, other researchers $^{(14)}$ showed modifications in swallowing behavior only after combined sour and cold stimuli, and did not after separate cold or sour stimuli. The different results between studies could be related to different citric acid concentrations.

Another study ${ }^{(23)}$ investigated the effect of moderate versus high taste concentration and barium taste samples on lingual swallowing pressure. The authors detected that the lingual swallowing pressures was higher with moderate concentration of sucrose and with high concentrations of salt and citric acid, compared with the pressures generated by water in a group of young adults. In contrast to what the authors expected, the higher taste concentration stimuli did not uniformly increase swallowing lingual pressures. Thus, they suggested that the concentration used in the study may not have been high enough to elicit the increased the sensory input to the nucleus tractus solitarius, with subsequent activation of more motor neurons in the ambiguous nucleus to evoke stronger lingual swallowing pressures compared with water. Based on these data, an issue to be further investigated would be the appropriate concentration of sour taste to elicit faster and broader responses.

In this context, the present study used $3 \mathrm{~g}$ of lemon flavor powder mixed with $40 \mathrm{~mL}$ of water. Considering that most subjects involved in our study reported that it was a nice taste, we may question whether the increase in sour taste concentration would lead to a faster motor response, with significant effects occurring when the sour taste stimulus is used alone. Moreover, the mean age of the subjects corresponded to the elderly range and, owing to the possible reduction of intraoral sensitivity in this population, more intense stimuli (with greater taste concentrations) could have triggered different motor responses.

In younger populations ${ }^{(24)}$ it was observed that sour and sweet tastes have evoked earlier activation of submentalis and infrahyoid muscles than the absence of stimuli. The same concentration of sour and sweet did not show difference in the elderly population. These findings could be the result of reduced perception of taste in the elderly population ${ }^{(24)}$.
Also showing the benefit of sour taste in oral preparations, it was observed ${ }^{(25)}$ both the reduced oral preparation time and greater amplitude of submentalis muscle contraction with sour taste stimulus than other stimuli. The authors stated that prolonged contraction may allow the hyoid to remain elevated for longer periods, supporting the reduction of aspiration risks.

Similar results, i.e., an increase in the amplitude of submentalis muscle contraction during sour food swallowing, when compared to water swallowing, was showed by several studies ${ }^{(25-27)}$, and they recommended the use of sour taste as part of the rehabilitation process.

Likewise, based on our results (Table 1), we believe that the sour taste associated with cold temperature (in a pasty consistency), could be used as part of the rehabilitation of dysphagic patients in order to facilitate swallowing. The main hypothesis suggested in another research ${ }^{(13)}$ to explain the facilitated swallowing in the presence of high intensity stimuli, similar to this study, is that sour taste could be related to increased salivation and increased sensory inputs. Concerning salivation, this hypothesis ${ }^{(13)}$ was that a quick increase in salivation caused by a sour bolus would consequently increase the volume of the food bolus. As a consequence, and as described in previous studies $^{(10)}$, the increased volume of the food bolus could lead to a reduced oral phase time, such as the time between the onset of swallowing and the pharyngeal response, facilitating the swallowing dynamics. However, this hypothesis depends on the confirmation that sour stimuli could cause increased salivation. Thus, researchers ${ }^{(28)}$ in an experimental study with rats tried to eliminate the influence of salivation by connecting the three main ducts of the salivary glands. By adopting this procedure they obtained the same results, which favored swallowing. Therefore, they suggested that the main reason why a sour taste facilitated swallowing was the increase in sensory inputs to the swallowing centers through sensory nerves, leading to changes in the modulation of swallowing.

Likewise, we suggest that reduction in oral transit time (OTT and TOTT) is due to the increase in sensory inputs, activating taste receptors as well as temperature receptors, and thus facilitating swallowing.

Studies have suggested that the increase in sensory inputs may increase subject awareness of the bolus, modifying swallowing behavior ${ }^{(3,14)}$. In these studies, the authors observed that a reduction in volume per swallow and swallowed volume per second occurred with a sour bolus ${ }^{(3,14)}$. Both studies supported the notion that the increase in sensory afference might have generated the perception of a mild "harmful" stimulus. Such stimulus might have rendered the bolus perception more 
conscious, attracting the subject's attention and leading him to swallow more carefully.

Based on authors referred ${ }^{(3,14)}$, the reduction of transit time may be attributed to greater perception of the bolus, rendering it more conscious, facilitating the oral control and consequently leading to a faster motor response.

\section{CONCLUSION}

This study showed that the combination of thermal and chemical stimuli (sour taste and cold temperature) reduced OTT and TOTT in patients after stroke.

* ARG, PCC and PWR carried out data acquisition; ARG and PCC analyzed the exams and revised the text; ARG elaborated the text; MACAH was the work advisor and RGS and AOS were the official co-advisors of the research and all participated of text preparation and correction; AAS participated of analysis program elaboration and LRCC participated of consultancy and statistical analysis.

\section{REFERENCES}

1. Michou E, Hamdy S. Cortical input in control of swallowing. Curr Opin Otolaryngol Head Neck Surg. 2009;17:166-71.

2. Hiss SG, Strauss M, Treole K, Stuart A, Boutilier S. Effects of age, gender, bolus volume, bolus viscosity, and gustation on swallowing apnea onset relative to lingual bolus propulsion onset in normal adults. J Speech Lang Hear Res. 2004; 47:572-83.

3. Chee C, Arshad S, Singh S., Mistry S, Hamdy S. The Influence of chemical gustatory stimuli and oral anaesthesia on healthy human pharyngeal swallowing. Chem Senses. 2005;30:393-400.

4. Teismann IK, Steinstraeter O, Stoeckigt K et al. Functional oropharyngeal sensory disruption interferes with the cortical control of swallowing. BMC Neurosci. 2007;8:62.

5. Ertekin C, Kiylioglu N, Tarlaci S, Keskin A, Aydogdu I. Effect of mucosal anaesthesia on oropharyngeal swallowing. Neurogastroenterol Motil. 2000;12:567-72.

6. Aviv JE, Sacco RL, Thomson J, et al. Silent laryngopharyngeal sensory deficits after stroke. Ann Otol Rhinol Laryngol. 1997;106:87-93.

7. Schelp AO, Cola PC, Gatto AR, Silva RG, Carvalho LR. Incidência de disfagia orofaríngea após acidente vascular encefálico em hospital público de referência. Arq Neuro-Psiquiatr. 2004;62:503-6.

8. Mann G, Hankey GJ, Cameron D. Swallowing function after stroke: prognosis and prognostic factors at 6 months. Stroke, 1999;30:744-748.

9. Kim IS, HamTR. Influence of mastication and salivation on swallowing in stroke patients. Arch Phys Med Rehabil. 2005;86:1986-90.

10. Power ML, Hamdy S, Singh S, Tyrrell PJ, Turnbull I, Thompson DG Deglutitive laryngeal closure in stroke patients. J Neurol Neurosurg Psychiatry. 2007;78:141-6.
11. Power ML, Hamdy S, Goulermas JY, Tyrrell PJ, Turnbull I, Thompson DG. Predicting Aspiration After Hemispheric Stroke from Timing Measures of Oropharyngeal Bolus Flow and Laryngeal Closure. Dysphagia. 2009;24:257-64.

12. Robbins J, Hamilton JW, Lof GL, Kempster GB. Oropharyngeal swallowing in normal adults of different ages. Gastroenterology. 1992;10:823-9.

13. Logemann JA; Pauloski RB ; Colangelo L ; Lazarus C; Fujiu M; Kahrilas PJ. Effects of a sour bolus on oropharyngeal swallowing measures in patients with neurogenic dysphagia. J Speech Hear Res. 1995;38:556-63.

14. Hamdy S., Jilani S, Price V, Parker C, Hall N, Power M. Modulation of human swallowing behavior by thermal and chemical stimulation in health and after brain injury. Neurogastroenterol Motil. 2003;15:69-77.

15. Pelletier CA, Lawless HT. Effect of citric acid and citric acid-sucrose mixtures on swallowing in neurogenic oropharyngeal dysphagia. Dysphagia. 2003;18:231-41.

16. Cola, PC, Gatto, AR, Silva RG, Schelp AO, Henry MACA. Reabilitação em disfagia orofaríngea neurogênica: sabor azedo e temperatura fria. Revista CEFAC. 2008;10:200-5.

17. Cola PC; Gatto AR; Silva RG; Spadotto AA; Schelp AO; Henry MACA. The influence of sour taste and cold temperature in pharyngeal transit duration in patients with stroke. Arq. Gastroenterol. 2010;47:18-21.

18. Ott D, Hodge R, Pikna LA, Chen M, Gelfand D. Modified barium swallow: clinical and radiographic correlation and relation to feeding recommendations. Dysphagia. 1996;11:93-8.

19. Martin-Harris B, Brodsky MB, Michel Y, Lee F, Walters B. Delayed initiation of the pharyngeal swallow: normal variability in adult swallows. J Speech Hear Res. 2007;50:585-94.

20. Dziewas R, Warnecke T, Olenberg S, et al. Towards a basic endoscopic assessment of swallowing in acute stroke - development and evaluation of a simple dysphagia score. Cerebrovasc Dis. 2008;26:41-7.

21. Spadotto AA, Gatto AR, Cola PC, et al. Software para análise quantitativa da deglutição. Radiol Bras. 2008;41:25-8.

22. Sciortino KF, Liss JM, Case JL, Gerritsen KGM, Katz RC. Effects of mechanical, cold, gustatory, and combined stimulation to human anterior faucial pillars. Dysphagia. 2003;18:16-26.

23. Pelletier CA, Dhanaraj GE. The effect of taste and palatability on lingual swallowing pressure. Dysphagia. 2006;121-8.

24. Ding R, Logemann JA, Larson CR, Rademaker AW. The effects of taste and consistency on swallow physiology in younger and older healthy individuals: a surface electromyographic study. J Speech Lang Hear Res. 2003;46:977-89.

25. Leow LP, Huckabee ML, Sharma S, Tooley TP. The influence of taste on swallowing apnea, oral preparation time, duration and amplitude of submental muscle contraction. Chem Senses. 2007;32:119-28.

26. Miura Y, Morita Y, Koizumi H, Shingai T. Effects of taste solutions, carbonation, and cold stimulus on the power frequency content of swallowing submental surface electromyography. Chem Senses. 2009;34:325-31.

27. Palmer PM, McCulloch TM, Jaffe D, Neel AT. Effects of a sour bolus on the intramuscular electromyographic (EMG) activity of muscles in the submental region. Dysphagia. 2005;20:210-17.

28. Kajii Y, Shingai T, Kitagawa J, Takahashi Y, Taguchi Y, Noda T, et al. Sour taste stimulation facilitates reflex swallowing from the pharynx and larynx in the rat. Physiol Behav. 2002;77:321-25. 